\title{
Treatment of Mycoplasma Contamination in Cell Cultures with Plasmocin
}

\author{
Cord C. Uphoff, Sabine-A. Denkmann, and Hans G. Drexler \\ Department of Human and Animal Cell Lines, Leibniz Institute DSMZ-German Collection of Microorganisms and Cell Cultures, \\ 38124 Braunschweig, Germany \\ Correspondence should be addressed to Cord C. Uphoff, cup@dsmz.de
}

Received 18 April 2012; Revised 11 June 2012; Accepted 21 June 2012

Academic Editor: Elvira Gonzalez De Mejia

Copyright ( $\odot 2012$ Cord C. Uphoff et al. This is an open access article distributed under the Creative Commons Attribution License, which permits unrestricted use, distribution, and reproduction in any medium, provided the original work is properly cited.

\begin{abstract}
A high percentage of cell lines are chronically infected with various mycoplasma species. The addition of antibiotics that are particularly effective against these contaminants to the culture medium during a limited period of time is a simple, inexpensive, and very practical approach for decontaminating cell cultures. Here, we examined the effectiveness of the new antimycoplasma compound Plasmocin that has been employed routinely to cleanse chronically infected cell lines. In a first round of treatment 45 out of $58(78 \%)$ mycoplasma-positive cell lines could be cured. In a second attempt using back-up cryopreserved original cells, four additional cell lines were cured; thus, the overall cure rate was $84 \%$. Even if the mycoplasma contamination was not eradicated by Plasmocin, the parallel treatment with several other antibiotics (Baytril, BM-Cyclin, Ciprobay, MRA, or MycoZap) led to the cure of all 58 cell lines. The successful decontamination was permanent as mycoplasmas were no longer detected at day +14 posttreatment and at later time points as examined by PCR which is the most sensitive and specific mycoplasma detection method. Collectively, our results highlight certain antibiotics as effective antimycoplasma reagents and support the therapeutic rationale for their use in the eradication of this notorious cell culture contaminant.
\end{abstract}

\section{Introduction}

Over the last decades, cell culture has become an important research tool for a variety of biomedical disciplines. One of the major problems of the cell culture field appears to be infection with mycoplasma that basically has been known since the beginning of this technology. It has been estimated that between $5 \%$ and $35 \%$ of cell cultures are contaminated with mycoplasma [1]. The six species Acholeplasma laidlawii, Mycoplasma arginini, M. fermentans, M. hominis, M. hyorhinis, and $M$. orale account for the vast majority of infections $[2,3]$. Mycoplasma can alter a great variety of cellular characteristics and can affect every cellular parameter, often leading to experimental artefacts and spurious results.

Numerous methods for detecting mycoplasma infection have been developed [4]. For a long time, microbiological cultivation in broth and subsequently on agar was regarded as the most sensitive and specific procedure and was commonly used as the reference method (the "gold standard"). However, newer test systems based on molecular biological aspects have been described, which have a sensitivity and reliability surpassing the classical methods, in particular polymerase chain (PCR) is now the method of choice (reviewed in detail in [5]). Hence, the issue of detecting mycoplasma infection seems to be solved.

The best option for mycoplasma-infected cell cultures is to discard infected cultures and to replace them with fresh stocks that are known to be mycoplasma-free [6]. This approach may not always be feasible, and hence a wide spectrum of different elimination methods have been devised (reviewed in $[4,7]$ ). The technically simplest alternative and overall the most practical way to solve this problem is antibiotic treatment. The availability of a range of antibiotics that have particularly strong activity against mycoplasmas makes it the method of choice.

Recently, a new antimycoplasma antibiotic compound termed Plasmocin has become available. The aims of the present study were (1) to determine the effectiveness of Plasmocin in eliminating mycoplasmas from infected cultures, 
TABLE 1: Oligonucleotide primers used for the PCR detection of mycoplasma contamination.

\begin{tabular}{|c|c|c|c|c|}
\hline Forward primers & GC cont. & Melting temp. & Cell culture mycoplasma species* & $\begin{array}{l}\text { Amplicon size } \\
\text { (bp) }\end{array}$ \\
\hline cgc ctg agt agt acg ttc gc & $60 \%$ & $62.5^{\circ} \mathrm{C}$ & M. fermentans, M. bovis & 518 \\
\hline cgc ctg agt agt acg tac gc & $60 \%$ & $62.5^{\circ} \mathrm{C}$ & Acholeplasma laidlawii & 525 \\
\hline tgc ctg ggt agt aca ttc gc & $55 \%$ & $60.5^{\circ} \mathrm{C}$ & Ureaplasma spp. & 504 \\
\hline tgc ctg agt agt aca ttc gc & $50 \%$ & $58.4^{\circ} \mathrm{C}$ & M. gallisepticum & 504 \\
\hline cgc ctg agt agt atg ctc gc & $60 \%$ & $62.5^{\circ} \mathrm{C}$ & $\begin{array}{l}\text { M. arginini, M. hominis, M. hyorhinis, M. orale, } \\
\text { M. pneumoniae }\end{array}$ & $\begin{array}{l}520,522,518 \\
520,517\end{array}$ \\
\hline cac ctg agt agt atg ctc gc & $55 \%$ & $60.5^{\circ} \mathrm{C}$ & M. pulmonis & 518 \\
\hline cgc ctg ggt agt aca ttc gc & $60 \%$ & $62.5^{\circ} \mathrm{C}$ & M. pirum & 504 \\
\hline \multicolumn{5}{|l|}{ Reverse primers } \\
\hline gcg gtg tgt aca aga ccc ga & $60 \%$ & $62.5^{\circ} \mathrm{C}$ & $\begin{array}{l}\text { M. arginini, } M . \text { bovis, } M . \text { fermentans, } \text {. gallisepticum, } \\
\text { M. hominis, } \text { M. orale, } M . \text { pirum, Ureaplasma spp. }\end{array}$ & \\
\hline gcg gtg tgt aca aaa ccc ga & $55 \%$ & $60.5^{\circ} \mathrm{C}$ & M. hyorhinis, M. pneumoniae & \\
\hline gcg gtg tgt aca aac ccc ga & $60 \%$ & $62.5^{\circ} \mathrm{C}$ & A. laidlawii & \\
\hline
\end{tabular}

* Only those mycoplasma species are listed that predominantly occur in cell cultures or represent groups of mycoplasmas (e.g., Ureaplasma spp., M. pulmonis, and M. pirum). Most of the other mycoplasma species are also detected using the primers.

(2) to compare Plasmocin with other reagents known to be highly effective, (3) to examine whether any resistance can be overcome by a second round of treatment with Plasmocin or other compounds, (4) to identify culture conditions that may be helpful in preventing antibiotic resistance and loss of cell culture due to cytotoxicity, and (5) to propose a practical mycoplasma treatment approach.

\section{Materials and Methods}

2.1. Cultivation of Cell Lines. The fifty-eight mycoplasmainfected cell lines used in this study were all continuous human or animal cell lines growing in suspension or adherent in standard plastic plates or in flasks (Nunc Thermo Fisher, Langenselbold, Germany) in basic growth media (Gibco Life Technologies, Darmstadt, Germany) supplemented with 5-20\% mycoplasma-free, heat-inactivated fetal bovine serum (FBS) (Sigma, München, Germany) under standard cell culture conditions (at $37^{\circ} \mathrm{C}$, in $5 \% \mathrm{CO}_{2}$ and $90 \%$ humidity). No other supplements (including antibiotics) were routinely added. None of the cell lines were deliberately infected with mycoplasmas, hence all samples represented chronically contaminated cultures. Cultures were passaged according to standard procedures $[8,9]$.

2.2. Mycoplasma Detection and Species Identification by PCR. The previously described PCR method was used for the verification of mycoplasma contamination [10, 11]. Cell culture supernatants $(1 \mathrm{~mL})$ were centrifuged for $6 \mathrm{~min}$ at $13,000 \mathrm{~g}$. The resulting supernatants were discarded and the pellets were washed twice with phosphate-buffered saline (PBS). After the second wash, the pellets were resuspended in $100 \mu \mathrm{L} \mathrm{PBS}$ and incubated for $15 \mathrm{~min}$ at $95^{\circ} \mathrm{C}$. The DNAs were extracted with "Wizard DNA Clean-Up System" (Promega, Mannheim, Germany) according to the manufacturer's instructions; the DNAs were eluted from the column

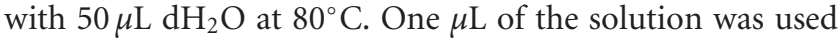
for the PCR amplification. The PCR was carried out in a final volume of $25 \mu \mathrm{L}$ in 1X PCR buffer (Invitrogen, Karlsruhe, Germany) without $\mathrm{MgCl}_{2}, 1.5 \mathrm{mM} \mathrm{MgCl}_{2}, 100 \mu \mathrm{M}$ dNTPs (each), and $0.1 \mu \mathrm{M}$ of each oligonucleotide. The oligonucleotides designed and their physical properties are listed in Table 1. Furthermore, $1 \mu \mathrm{L}$ internal control DNA and 1.25 U Platinum Hot Start Taq DNA polymerase (Invitrogen) were added to the PCR reaction mixture (the method was described in detail in [12]).

The amplification was started with the activation of the Hot Start Taq polymerase at $96^{\circ} \mathrm{C}$ for $2 \mathrm{~min}$. After this initial cycle, 35 cycles of $94^{\circ} \mathrm{C}$ for $4 \mathrm{~s}, 65^{\circ} \mathrm{C}$ for $8 \mathrm{~s}$, and $72^{\circ} \mathrm{C}$ for $16 \mathrm{~s}$ were run on the Applied Biosystems GeneAmp PCR System 9700 (Applied Biosystems, Darmstadt, Germany). The amplification step was extended by $2 \mathrm{~s}$ after each cycle. Ten $\mu \mathrm{L}$ of the reaction mix was electrophoresed on a $1.4 \%$ agarose gel, stained with ethidium bromide, visualized under ultraviolet light, and photographed. Depending on the mycoplasma species, the amplification product is $515-525 \mathrm{bp}$ long.

The internal control was prepared as described previously [11] by cloning the PCR amplification product of $A$. laidlawii into the pGEM-T vector (Promega, Mannheim, Germany) and amplified in E. coli. Using Sfu I the resulting plasmid pMyco-GEM-T was linearized and a 476 bp Taq I fragment from pHMSE-1 was ligated into the $S f u$ site. Using this plasmid a 986 bp fragment is competitively amplified in the PCR reaction when A. laidlawii is the contaminating mycoplasma species and noncompetitively amplified when other mycoplasma species are present in the cell cultures.

The identification of those mycoplasma species that occur predominantly in cell cultures was carried out by digestion of the PCR products with various restriction enzymes. The restriction enzymes used and the restriction fragment patterns obtained for the different species have 


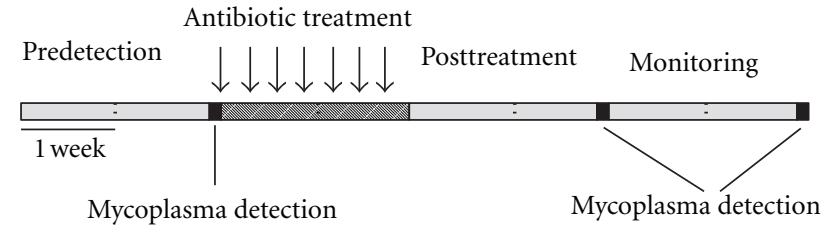

Figure 1: Treatment protocol for Plasmocin. The reagent is added to the medium at a final concentration of $25 \mu \mathrm{g} / \mathrm{mL}$ on the days indicated by arrows.

been listed in table form previously [12]. The restriction fragment patterns were determined by electrophoresis in a $1.5 \%$ agarose gel and visualized by ethidium bromide staining.

2.3. Antimycoplasma Treatment. Culturing during the antimycoplasma treatment was performed as follows. Spent medium of each cell line was replaced with fresh medium to which one of the various antibiotics was added during the treatment period (addition of antibiotics directly to the culture and not to the stored medium; antibiotic dilutions were freshly prepared for each treatment cycle). Cultures were always thoroughly mixed in order to ensure optimal distribution of the reagents and access of the reagents to the mycoplasma cells, which are commonly attached to the eukaryotic cell membrane. It is important to break up cell clusters and clumps as in such situations mycoplasma cells may be trapped and the antibiotics may not have physical access.

During the treatment periods, cultures were kept at higher cell densities and grown with higher concentrations of FBS than usually employed (5-10\% higher concentration of FBS) to counterbalance the possible toxic or growthinhibitory effects of the antibiotics with enhanced proliferation. Cultures were treated in flasks in volumes of $10-20 \mathrm{~mL}$. Some suspension cell lines were grown in 24-well plates with volumes of 1-2 mL per well. These plates are optimal for handling the cells (pipetting, splitting, etc.) and for the daily observation of the cells under the inverted microscope.

At the end of the treatment periods of 7-21 days, cells were washed twice and resuspended in fresh complete medium without any antimycoplasma antibiotics or any other antibiotics. Cells were then grown antibiotic-free for at least two weeks in order to enrich any residual mycoplasmas up to detectable levels or to get rid of any residual mycoplasmal DNA that may give a false-positive signal in the PCR analysis. The mycoplasma status of all cultures was then examined after this posttreatment period by the abovedescribed PCR method. In most instances, the cells were further cultured and reexamined in almost two-week intervals.

2.4. Antimycoplasma Antibiotics. A short summary of the treatment protocols is shown graphically in Figure 1. Fluoroquinolones (Baytril, Ciprobay, MRA, and one of the two components of Plasmocin) are bactericidal, inhibiting nucleic acid synthesis. Macrolides (like tiamulin in BMCyclin I and one of the two components of Plasmocin) and tetracyclines (like minocycline in BM-Cyclin II) are bacteriostatic, inhibiting the protein synthesis.

Baytril. Cells were treated with the quinolone enrofloxacin (Baytril; from Bayer, Leverkusen, Germany) for 14 days. The original ready-to-use solution with a concentration of $100 \mathrm{mg} / \mathrm{mL}$ was diluted $1: 10$ with RPMI 1640 medium; $25 \mu \mathrm{L}$ of the latter solution was added for each milliliter of culture volume (final concentration of $25 \mu \mathrm{g} / \mathrm{mL}$ ).

BM-Cyclin. Treatment with BM-Cyclin (Roche, Mannheim, Germany) included BM-Cyclin I containing the macrolide tiamulin for 3 days followed by BM-Cyclin II containing the tetracycline minocycline for 4 days. This alternating cycle was applied three times for a total of 21 days of treatment. The final concentrations of BM-Cyclin I and of BM-Cycli II were $10 \mu \mathrm{g} / \mathrm{mL}$ ( $4 \mu \mathrm{L}$ of a $2.5 \mu \mathrm{g} / \mathrm{mL}$ stock solution per $\mathrm{mL}$ of cell culture medium) and $5 \mu \mathrm{g} / \mathrm{mL}(4 \mu \mathrm{L}$ of a $1.25 \mu \mathrm{g} / \mathrm{mL}$ stock solution per $\mathrm{mL}$ of cell culture medium), respectively.

Ciprobay. Cells were exposed to the fluoroquinolone ciprofloxacin (Ciprobay 100; Bayer) at $10 \mu \mathrm{g} / \mathrm{mL}(=5 \mu \mathrm{L} / \mathrm{mL})$ for 14 days.

MRA. The Mycoplasma Removal Agent (MRA; from ICN, Eschwege, Germany) contains a nondisclosed fluoroquinolone and was added to cell cultures at $0.5 \mu \mathrm{g} / \mathrm{mL}(=10 \mu \mathrm{L} / \mathrm{mL})$. Cultures were treated for 7 days.

MycoZap. MycoZap (Lonza, Verviers, Belgium) contains a surface-active peptide (reagent 1 ) and an antibiotic (reagent 2) and was employed for 20 days: reagent 1 at $0.5 \mathrm{~mL}$ per $4.5 \mathrm{~mL}$ cell culture medium (with maximally $5 \% \mathrm{FBS}$ ) for the first 5 days was followed by reagent 2 at $0.5 \mathrm{~mL}$ per $4.5 \mathrm{~mL}$ cell culture medium (with normal FBS concentration) for another 15 days.

Plasmocin. Treatment with the compound preparation Plasmocin (InvivoGen, Toulouse, France) was performed for 14 days at $25 \mu \mathrm{g} / \mathrm{mL}(=1 \mu \mathrm{L} / \mathrm{mL})$. Plasmocin contains a mixture of a fluoroquinolone and a macrolide [14].

\section{Results}

In total 58 positive cell lines were treated with various antibiotics known to be effective against mycoplasma. These cell lines were all chronically infected with mycoplasma and were not only experimentally, short-term contaminated cultures. Mycoplasma has long-term effects on the eukaryotic cells and some interactions might have developed. Mycoplasma infection was verified by the specific PCR assay; the contaminating species was determined for 54 cell lines (Table 2). The possible outcomes of treatment were (1) cured, that is, complete and permanent freedom from mycoplasma infection; (2) resistant, the treatment was not successful and the culture remained mycoplasma-positive; (3) dead, the culture is lost presumably due to cytotoxic 
TABle 2: Treatment of Mycoplasma-Positive Cell Lines with Various Antibiotics.

\begin{tabular}{|c|c|c|c|c|c|c|c|}
\hline Mycoplasma & Cell line & Species & Tissue/cell type & Plasmocin & BM-Cyclin & Baytril & Other $\mathrm{AB}$ \\
\hline \multirow{5}{*}{ A. laidlawii } & HELA & Human & Cervix carcinoma & $\mathrm{C}$ & & $\mathrm{C}$ & \\
\hline & KYAE-1 & Human & Esophagus adenocarcinoma & $\mathrm{C}$ & $\mathrm{C}$ & & \\
\hline & Mz-ChA-1 & Human & Gall bladder & $\mathrm{C}$ & $\mathrm{C}$ & $\mathrm{C}$ & \\
\hline & Mz-ChA-2 & Human & Gall bladder & $\mathrm{C}$ & $\mathrm{C}$ & $\mathrm{R}$ & \\
\hline & PLT-2 & Human & Leukemia & $\mathrm{R} \rightarrow \mathrm{C}$ & $\mathrm{C}$ & & \\
\hline \multirow{6}{*}{ M. arginini } & A-431 & Human & Epidermoid carcinoma & C & $\mathrm{C}$ & & C (MycoZap) \\
\hline & BL-100 & Human & Lymphoma & $\mathrm{C}$ & $\mathrm{C}$ & $\mathrm{C}$ & \\
\hline & Cell line 1 & Syrian hamster & Embryo fibroblasts & $\mathrm{C}$ & $\mathrm{C}$ & & \\
\hline & Cell line 3 & Mouse & Hybridoma & $\mathrm{C}$ & & & \\
\hline & MYL & Human & Leukemia & $\mathrm{R}$ & $\mathrm{C}$ & $\mathrm{R}$ & \\
\hline & TA-5 & Mouse & Hybridoma & $\mathrm{C}$ & $\mathrm{R}$ & & C (MycoZap) \\
\hline M. arginini $+M$. fermentans & JEKO-1 & Human & Lymphoma & $\mathrm{D}$ & $\mathrm{C}$ & & \\
\hline \multirow{15}{*}{ M. fermentans } & CAL-1 & Human & Leukemia & $\mathrm{C}$ & $\mathrm{C}$ & $\mathrm{D}$ & \\
\hline & EB-3 & Human & Lymphoma & $\mathrm{C}$ & $\mathrm{C}$ & & C (MycoZap) \\
\hline & FPR2+HL60 & Human & Leukemia & $\mathrm{C}$ & $\mathrm{C}$ & $\mathrm{C}$ & C (Ciprobay) \\
\hline & HBL-2 & Human & Lymphoma & $\mathrm{C}$ & $\mathrm{C}$ & $\mathrm{C}$ & \\
\hline & JOK-1 & Human & Lymphoma & $\mathrm{C}$ & $\mathrm{D}$ & $\mathrm{C}$ & \\
\hline & KOPN-K & Human & Leukemia & $\mathrm{D}$ & $\mathrm{D}$ & $\mathrm{C}$ & \\
\hline & LAN-6 & Human & Neuroblastoma & $\mathrm{C}$ & $\mathrm{C}$ & $\mathrm{C}$ & \\
\hline & NALM-16 & Human & Leukemia & $\mathrm{C}$ & & $\mathrm{C}$ & \\
\hline & NBL-S & Human & Neuroblastoma & $\mathrm{C}$ & & $\mathrm{C}$ & \\
\hline & NCEB-1 & Human & Lymphoma & $\mathrm{C}$ & $\mathrm{C}$ & $\mathrm{R}$ & \\
\hline & NK-9 & Human & Leukemia & $\mathrm{C}$ & $\mathrm{C}$ & & C (MycoZap) \\
\hline & RAMOS & Human & Lymphoma & $\mathrm{D} \rightarrow \mathrm{C}$ & & $\mathrm{C}$ & \\
\hline & RI-1D & Human & Lymphoma & C & $\mathrm{C}$ & $\mathrm{C}$ & \\
\hline & SACHI & Human & Leukemia & $\mathrm{R} \rightarrow \mathrm{C}$ & $\mathrm{C}$ & $\mathrm{R}$ & $\mathrm{R}$ (MRA) \\
\hline & SKK-1 & Human & Leukemia & C & $\mathrm{C}$ & $\mathrm{C}$ & \\
\hline M. fermentans $+M$. hyorhinis & DND-39 & Human & Lymphoma & $\mathrm{C}$ & $\mathrm{D}$ & & \\
\hline M. fermentans + M. orale & LS & Human & Neuroblastoma & $\mathrm{C}$ & $\mathrm{C}$ & $\mathrm{C}$ & \\
\hline \multirow{19}{*}{ M. hyorhinis } & B6 & Pig & Intestinal cells & $\mathrm{D}$ & $\mathrm{C}$ & & \\
\hline & B10XI & Pig & Intestinal cells & $\mathrm{C}$ & $\mathrm{C}$ & $\mathrm{C}$ & \\
\hline & Cell line 4 & Mouse & Hybridoma & $\mathrm{C}$ & & & \\
\hline & Cell line 5 & Mouse & Hybridoma & $\mathrm{C}$ & & & \\
\hline & Cell line 6 & Mouse & Hybridoma & $\mathrm{C}$ & & $\mathrm{C}$ & \\
\hline & CIEB & Calf & Colon & $\mathrm{R}$ & $\mathrm{C}$ & $\mathrm{R}$ & \\
\hline & CLAB & Pig & Colon & $\mathrm{R}$ & $\mathrm{C}$ & $\mathrm{R}$ & \\
\hline & HBL-2 & Human & Lymphoma & $\mathrm{C}$ & $\mathrm{C}$ & $\mathrm{C}$ & \\
\hline & HEK-293 & Human & Embryo kidney & $\mathrm{C}$ & $\mathrm{C}$ & $\mathrm{C}$ & \\
\hline & MEF clone 1 & Mouse & Embryo fibroblasts & $\mathrm{C}$ & $\mathrm{R}$ & $\mathrm{C}$ & \\
\hline & MEF clone 2 & Mouse & Embryo fibroblasts & $\mathrm{C}$ & $\mathrm{R}$ & $\mathrm{C}$ & \\
\hline & MEL-IM & Human & Melanoma & $\mathrm{R}$ & $\mathrm{C}$ & $\mathrm{R}$ & \\
\hline & PANC-02 & Mouse & Pancreas carcinoma & $\mathrm{R}$ & $\mathrm{C}$ & $\mathrm{R}$ & \\
\hline & PC- 12 clone 1 & Rat & Pheochromocytoma & $\mathrm{C}$ & $\mathrm{C}$ & $\mathrm{C}$ & \\
\hline & PC-12 clone 2 & Rat & Pheochromocytoma & $\mathrm{C}$ & & $\mathrm{C}$ & C (Ciprobay) \\
\hline & PC-MDS & Human & Leukemia & $\mathrm{C}$ & $\mathrm{C}$ & $\mathrm{C}$ & \\
\hline & PSI & Pig & Colon & $\mathrm{R}$ & $\mathrm{C}$ & $\mathrm{R}$ & \\
\hline & SVG-A & Human & Glial cells & $\mathrm{C}$ & $\mathrm{C}$ & $\mathrm{C}$ & \\
\hline & WSU-DLCL-2 & Human & Lymphoma & $\mathrm{R} \rightarrow \mathrm{C}$ & & $\mathrm{R}$ & $\mathrm{R}$ (MRA) \\
\hline
\end{tabular}


TABle 2: Continued.

\begin{tabular}{|c|c|c|c|c|c|c|c|}
\hline Mycoplasma & Cell line & Species & Tissue/cell type & Plasmocin & BM-Cyclin & Baytril & Other $\mathrm{AB}$ \\
\hline \multirow{6}{*}{ M. orale } & Cell line 2 & Syrian hamster & Embryo fibroblasts & $\mathrm{C}$ & $\mathrm{C}$ & & \\
\hline & GI-ME-N & Human & Neuroblastoma & $\mathrm{C}$ & & $\mathrm{C}$ & \\
\hline & H-1963 & Human & Non-small-cell lung carcinoma & $\mathrm{C}$ & $\mathrm{C}$ & & \\
\hline & HCC-44 & Human & Non-small-cell lung carcinoma & C & & & \\
\hline & LAN-1 & Human & Neuroblastoma & $\mathrm{C}$ & & $\mathrm{C}$ & \\
\hline & NMB & Human & Neuroblastoma & $\mathrm{C}$ & & $\mathrm{C}$ & \\
\hline \multirow{4}{*}{ Not determined } & $\mathrm{CHO}$ clone 1 & Chinese hamster & Ovary & $\mathrm{C}$ & $\mathrm{C}$ & $\mathrm{C}$ & \\
\hline & CHO clone 2 & Chinese hamster & Ovary & $\mathrm{C}$ & $\mathrm{C}$ & $\mathrm{C}$ & \\
\hline & JW-8 & Mouse & Hybridoma & $\mathrm{C}$ & $\mathrm{C}$ & $\mathrm{C}$ & \\
\hline & U-266 & Human & Leukemia & $\mathrm{C}$ & $\mathrm{C}$ & $\mathrm{C}$ & \\
\hline
\end{tabular}

Outcome of treatment: C: cured; D: dead; R: resistant; $\rightarrow$ : back-up (untreated) mycoplasma-positive cells were treated in a second attempt.

$\mathrm{AB}$ : antibiotics (as indicated in table); cell lines 1-6: cell lines received for elimination of mycoplasma as service.

effects of the reagents on the eukaryotic cells which died during or shortly after treatment.

All cell lines were exposed to Plasmocin and to one or several other antimycoplasma antibiotics (Table 2). To that end, positive cell cultures were divided into several aliquots which were then treated in parallel. It is important to freeze also some positive cells as an untreated, cryopreserved backup of the original cells to be used in case the initial round of treatment leads to resistance or loss of the treated culture. In a first round of treatment $45 / 58(78 \%)$ cell lines could be cured with Plasmocin. The contaminating mycoplasmas of nine cell cultures (CIEB, CLAB, MEL-IM, MYL, PANC-02, PLT-2, PSI, SACHI, and WSU-DLCL-2) showed resistance to the antibiotic compounds of Plasmocin, corresponding to $15 \%$. Four of the 58 cell cultures (7\%) were lost by cell death during the treatment (B6, JEKO-1, KOPN-K, and RAMOS). In a second attempt using a back-up cryopreserved aliquot of the original positive cells, 4 additional cell lines (PLT2, RAMOS, SACHI, and WSU-DLCL-2) were cured, which brings the overall cure rate to $84 \%$ (Figure 2).

Taken together, even if a cell line was not cured by Plasmocin (or lost due to overwhelming cytotoxicity), the parallel treatment with several antibiotic options led to the cure of all 58 cell lines (Table 2). On aggregate, 156 cultures from 58 mycoplasma-positive cell lines were exposed to at least one of the six different antibiotic regimens. Overall, mycoplasma infection was eliminated by the various antibiotics in 124/156 (79\%) of the cultures treated. Singled out, the results for the other antibiotics are as follows (Figure 2): BM-Cyclin cured 38/44 (86\%) cell lines. Resistant mycoplasmas were present in the cell lines TA-5 (M. arginini), MEF clone 1, and MEF clone 2 (M. hyorhinis), whereas the cell lines JOK$1, \mathrm{KOPN}-\mathrm{K}$, and DND-39 were killed during the treatment. Baytril cured 31/42 (74\%) cell lines. The cell lines MzChA2 (A. laidlawii), MYL (M. arginini), NCEB-1 and SACHI (M. fermentans), CIEB, CLAB, MEL-IM, PANC-02, PSI, and WSU-DLCL-2 (M. hyorhinis) contained mycoplasmas resistant to the antibiotic, and only the cell line CAL-1 was lost under the regimen. MycoZap (4/4) and Ciprobay $(2 / 2)$ cured all mycoplasma-infected cell lines, although the number of treatments is not representative. MRA was

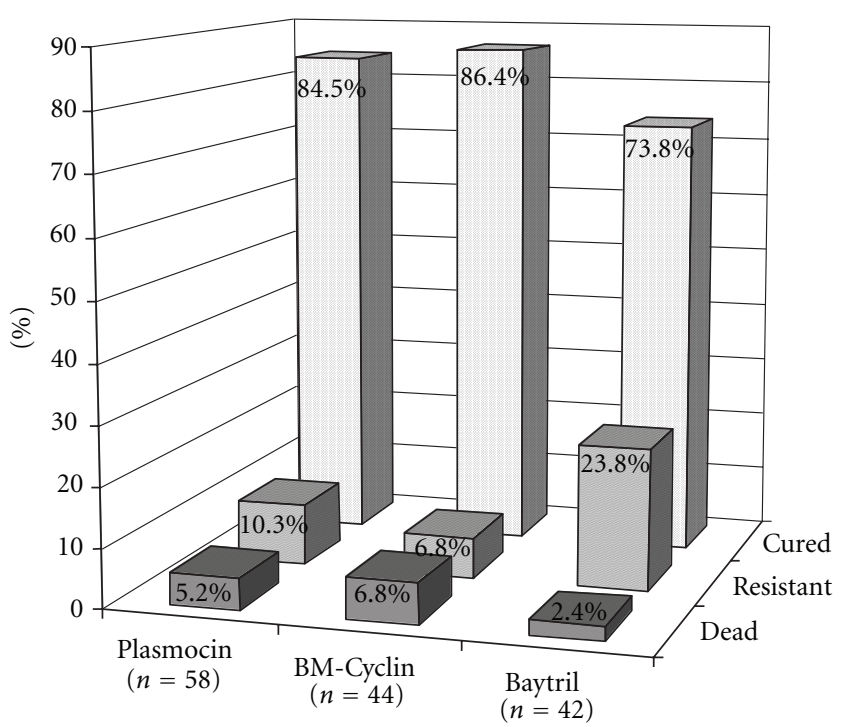

FIGURE 2: Relative treatment efficiency of antimycoplasma antibiotics. The portions given for Plasmocin include the results from second approaches.

not able to eliminate the mycoplasmas of the cell lines SACHI and WSU-DLCL-2, which showed also resistance to Plasmocin and Baytril. The successful decontamination was total and permanent as we did not detect any mycoplasma in the treated cultures at day +14 posttreatment or at later time points (as examined by PCR). An example of an agarose gel with positive and negative samples is shown in Figure 3. Hence, the cell cultures were cured.

The Plasmocin-resistant mycoplasma strains of the cell lines MYL, SACHI, CIEB, CLAB, MEL-IM, PANC-02, PSI, and WSU-DLCL-2 showed cross-resistance to Baytril or other fluoroquinolones, whereas the same cultures were cured by BM-Cyclin. Only two cell lines (Mz-ChA-2 and NCEB-1) were cured with Plasmocin but not by other fluoroquinolones. These results indicate that exposure to Plasmocin (containing two reagents) resembles very much the treatment with a single fluoroquinolone. 


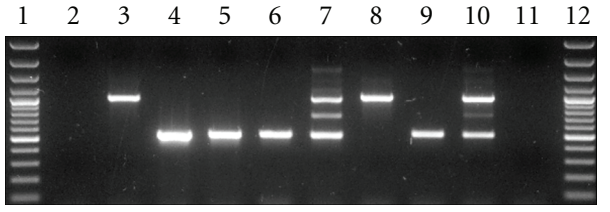

FIGURE 3: Agarose gel showing the results of a mycoplasma detection PCR. Two PCR reactions were performed per sample: one with the sample only and one with the sample and an internal control DNA added at a limiting dilution. The wild-type PCR product is represented by the lower band with a size of approximately $520 \mathrm{bp}$. The upper band is the amplification product of the internal control DNA (986 bp). (1) 100 bp ladder, (2) mycoplasma-negative cell line, (3) mycoplasma-negative cell line with internal control, (4) A. laidlawii-contaminated cell line, (5) A. laidlawii-contaminated cell line with internal control, (6) M. hyorhinis-contaminated cell line, (7) M. hyorhinis-contaminated cell line with internal control (the intermediate band at approximately $750 \mathrm{bp}$ is a hybrid of a $520 \mathrm{bp}$ and a 986 bp product), (8) internal control only, (9) positive control only, (10) positive control with internal control, (11) water control, and (12) 100 bp ladder.

The resistance to the antibiotics was not mycoplasma species specific. All M. orale strains $(n=6)$ were sensitive to Plasmocin. All but one of the cultures contaminated with either M. fermentans or A. laidlawii were cleansed, and these two resistant contaminations were eliminated in the second attempt.

\section{Discussion}

The eradication of mycoplasma contamination of continuous cell lines and the advent of specific antimycoplasma antibiotics together with the availability of the most sensitive and robust detection method, namely PCR, represent efficient methods to achieve mycoplasma-free cultures. Another combination treatment consisting of two antibiotics with different modes of action is provided by Plasmocin, which was shown here to be highly effective.

This high treatment efficacy of Plasmocin is illustrated by the percentage of successful outcomes: $84 \%$ of the cell lines $(n=58)$ were permanently cleansed of the mycoplasma contaminants while only $16 \%$ were either resistant to this treatment or lost due to presumably toxic effects of this antibiotic reagent on the eukaryotic cells.

For practical reasons each mycoplasma-positive cell line was divided into several aliquots and treated with at least two, but most often more, of the different antibiotic regimens found to be highly effective at our institute [15]. In the present study, on aggregate 156 cultures from 58 mycoplasma-positive cell lines were exposed to two or more of the six different antibiotic regimens. Thus, mycoplasma infection could be eliminated by at least one antibiotic reagent in all 58 cultures treated. It is of importance that this successful initial decontamination was total and permanent because we did not detect any mycoplasmas in the cured cultures after repeated testings (beginning 2 weeks at the earliest after the end of the treatment schedule), using PCR with specific primers.
Loss of cultures as a result of cell death occurred in 2-7\% of the treated cultures. However, these cell lines had arrived with rather low cell viability, and the cells did not grow very well or not at all, even questioning whether these "candidates for intensive cell culture care" would have survived without antibiotic exposure. The response of an already tattered cell culture to the addition of the antibiotic is not predictable. Many cultures recover immediately after starting the treatment due to the rapid reduction of the mycoplasmas, but for some perhaps more sensitive cell cultures the treatment is not able to reverse the already embarked path of cell death.

As not all cultures were cleansed by every antibiotic treatment, we encountered resistance rates in the range of 7-24\% (Plasmocin 10\%, BM-Cyclin 7\%, and Baytril 24\%). In the event of resistance or loss of culture the availability of frozen back-up mycoplasma-positive aliquots is of advantage. Here, four cell lines that were either resistant to Plasmocin (PLT2, SACHI, and WSU-DLCL-2) or lost (RAMOS) during treatment in the first round were exposed again in a second attempt. These efforts were successful in these four instances, emphasizing the usefulness to preserve mycoplasma-positive original cells as frozen back-ups for such second attempts. The reason for the different treatment outcome was not further investigated in detail, but altered cell culture methods (cell number, cell density, FBS concentration, culture vessels, passaging intervals, partial culture medium replacement, etc.) are likely to influence the success of the treatment.

Our extensive experience with the mycoplasma problem and the antibiotic treatment of contaminations led us to modify some of the standard cell culture parameters, in order to avoid culture loss and to minimize development of resistance. As the cells appear to be under strong stress, it was found to be of advantage to increase temporarily the FBS concentration to $20 \%$ and to culture cells at the maximum cell density in case of suspension cell lines or at semi- or near confluence in case of adherent cell lines. For some cell lines it is not advisable to exchange the culture medium completely (but only by half or two thirds) as these cells appear to produce autocrine growth factors. In this case the antibiotic concentration should be adjusted accordingly. That is the antibiotic concentration of the freshly added medium should be about $50 \%$ to $25 \%$ higher, respectively, to compensate for the degradation of the antibiotics in the spent medium.

Although we recommend a regular treatment schedule (exchange of spent medium with fresh complete medium to which the antibiotics are added), occasionally a break of 1-2 days in the treatment approach might be necessary if the viability of the cell culture decreases in consequence of the antibiotic treatment. Earlier investigations showed that the treatment with BM-Cyclin was more toxic compared to other fluoroquinolones (11\% of culture loss) [13]. The current study revealed less rates of culture losses for BMCyclin (approximately 7\%). However, the rate is still almost $2 \%$ higher than that of Plasmocin. We observed that some cell cultures exposed to BM-Cyclin deteriorate considerably several days after termination of the treatment, possibly due to a delayed effect, which may have caused impairment of mitochondrial or other intracellular functions. 


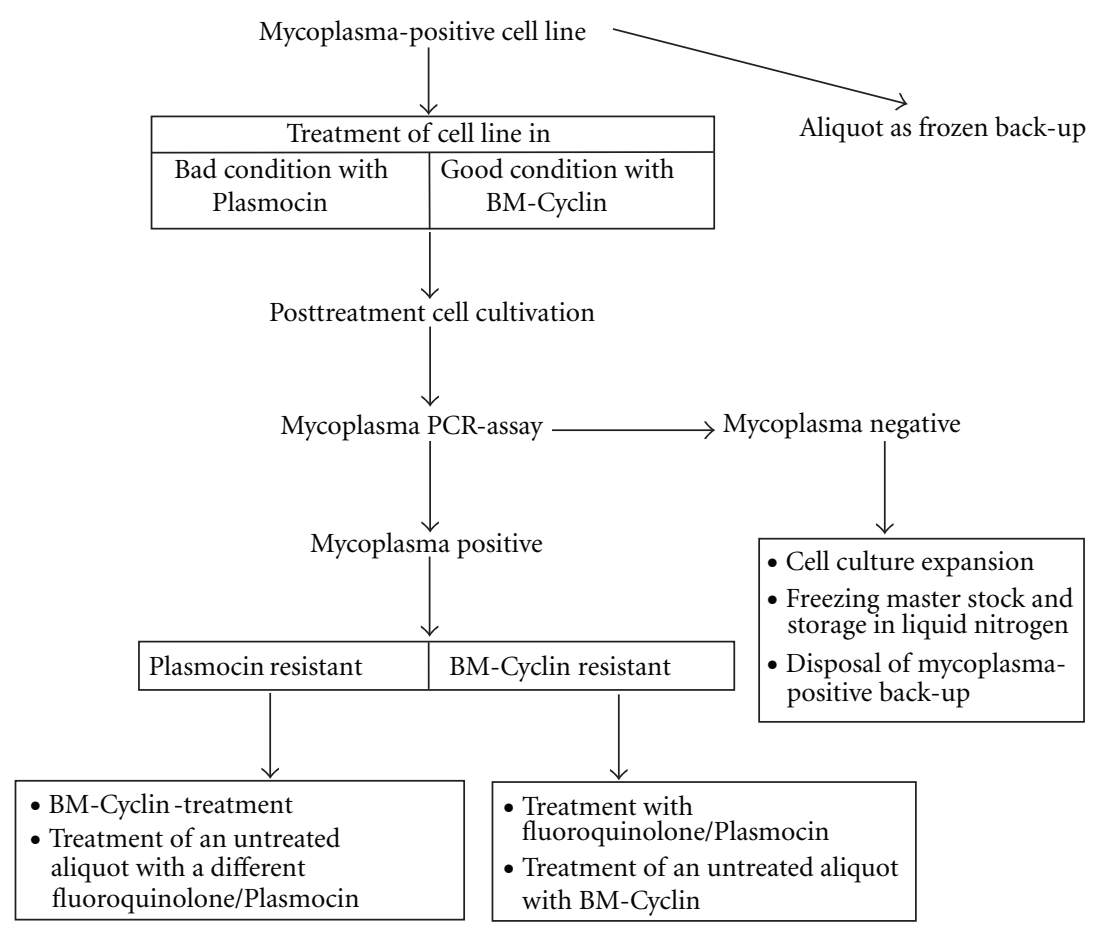

FIGURE 4: Approach to treatment of mycoplasma-positive cell cultures with specific antibiotics. The scheme was adapted from [13].

Most mycoplasma-positive cell cultures contain clusters or clumps of cells. Such cell aggregates which may represent sanctuaries for the microorganisms should be broken up by all means, gently but thoroughly. The proper implementation of the elimination procedure seems to be important for the curation rates. Mariotti et al. found permanent elimination of mycoplasmas from cell cultures with similar antibiotics from 29\% (MRA) to 57\% (BM-Cyclin) [16]). In particular, the frequent exchange of the medium associated with a constant reduction of mycoplasmas might be favorable.

Although Plasmocin consists of two antibiotics of different classes (an inhibitor of DNA replication and an inhibitor of protein biosynthesis), we found a similar outcome (successful cure or resistance) as seen with the fluoroquinolones used as single agents. Thus, there is no apparent synergistic effect by the combination of the antibiotics in Plasmocin; on the other hand we did not observe any negative effect of the combination with regard to the condition of the eukaryotic cells. MycoZap also consists of two successively applied components. The first reagent is a membrane-active peptide that kills and reduces most of the mycoplasmas in the absence or at low concentrations of FBS very quickly, whereas the second antibiotic is intended to destroy the remaining mycoplasmas. The method is described to be more effective and protective to the eukaryotic cells than fluoroquinolones alone $[16,17]$.

Fluoroquinolones Baytril and Plasmocin showed almost identical results regarding the occurrence of resistance (two of the Baytril-resistant cell cultures were cured by Plasmocin). Two of the initially Baytril/Plasmocin-double resistant cultures could be cleansed in the second round of treatment with Plasmocin.

We discourage the routine addition of antimycoplasma antibiotics to the culture medium as suboptimal concentrations of these reagents may not erase the contaminants but may obscure detection of low-level infection. Furthermore, continued exposure to antimycoplasma antibiotics may surely lead to the selection of resistant strains and thereby jeopardize any therapeutic options.

We have summarized our experience in a treatment algorithm (Figure 4). It is important to preserve mycoplasmapositive cells as cryopreserved back-ups. Any of the highly effective antibiotics may be used, in our hands antibiotics of the fluoroquinolone, macrolide and tetracycline classes were the most effective and easy to use. It is mandatory to document the outcome by a specific PCR assay (or other sensitive assays such as for example DNA-RNA hybridization GenProbe, MycoAlert, microbiological culture) in order to verify complete and permanent freedom from mycoplasma. Furthermore, while antibiotics can definitely cure infected cultures, regular monitoring is, however, necessary as reinfection can occur at any time point during the culture of cell lines.

\section{Conclusion}

The treatment with Plasmocin is an effective method to eliminate mycoplasma from infected cultures. Using different reagents and schedules in parallel (or, if necessary, sequentially) eradication of mycoplasma with antibiotic treatment is a time-consuming but nevertheless efficient option. 


\section{References}

[1] L. Young, J. Sung, G. Stacey, and J. R. Masters, "Detection of Mycoplasma in cell cultures," Nature protocols, vol. 5, no. 5, pp. 929-934, 2010.

[2] G. Bolske, "Survey of the mycoplasma infections in cell cultures and a comparison of detection methods," Zentralblatt fur Bakteriologie Mikrobiologie und Hygiene, vol. 269, no. 3, pp. 331-340, 1988.

[3] F. Kong, G. James, S. Gordon, A. Zelynski, and G. L. Gilbert, "Species-specific PCR for identification of common contaminant mollicutes in cell culture," Applied and Environmental Microbiology, vol. 67, no. 7, pp. 3195-3200, 2001.

[4] C. C. Uphoff and H. G. Drexler, "Mycoplasma contamination of cell cultures," in Encyclopedia of Industrial Biotechnology: Bioprocess, Bioseparation, and Cell Technology, M. C. Flickinger, Ed., pp. 3611-3630, John Wiley \& Sons, New York, NY, USA, 2010.

[5] D. V. Volokhov, L. J. Graham, K. A. Brorson, and V. E. Chizhikov, "Mycoplasma testing of cell substrates and biologics: review of alternative non-microbiological techniques," Molecular and Cellular Probes, vol. 25, no. 2-3, pp. 69-77, 2011.

[6] R. I. Freshney, Culture of Animal Cells, John Wiley \& Sons, Hoboken, NJ, USA, 6th edition, 2010.

[7] H. G. Drexler and C. C. Uphoff, "Mycoplasma contamination of cell cultures: incidence, sources, effects, detection, elimination, prevention," Cytotechnology, vol. 39, no. 2, pp. 75-90, 2002.

[8] DSMZ-German Collection of Microorganisms and Cell Cultures: Catalogue of Human and Animal Cell Lines, 2012.

[9] H. G. Drexler, Guide To Leukemia-Lymphoma Cell Lines, vol. 2, DSMZ, Braunschweig, Germany, 2010.

[10] A. Hopert, C. C. Uphoff, M. Wirth, H. Hauser, and H. G. Drexler, "Specificity and sensitivity of polymerase chain reaction (PCR) in comparison with other methods for the detection of mycoplasma contamination in cell lines," Journal of Immunological Methods, vol. 164, no. 1, pp. 91-100, 1993.

[11] C. C. Uphoff and H. G. Drexler, "Comparative PCR analysis for detection of mycoplasma infections in continuous cell lines," In Vitro Cellular \& Developmental Biology-Animal, vol. 38, no. 2, pp. 79-85, 2002.

[12] C. C. Uphoff and H. G. Drexler, "Detecting Mycoplasma contamination in cell cultures by polymerase chain reaction," Methods in Molecular Medicine, vol. 731, pp. 93-103, 2011.

[13] C. C. Uphoff, C. Meyer, and H. G. Drexler, "Elimination of mycoplasma from leukemia-lymphoma cell lines using antibiotics," Leukemia, vol. 16, no. 2, pp. 284-288, 2002.

[14] W. A. Cafruny, R. G. Duman, R. R. Rowland, E. A. Nelson, and G. H. Wong, "Antibiotic-mediated inhibition of porcine reproductive and respiratory syndrom virus (PRRSV) infection: a novel quinolone function which potentiates the antiviral cytokine response in MARC-145 cells and pig macrophages," Virology, vol. 1, pp. 17-28, 2008.

[15] C. C. Uphoff and H. G. Drexler, "Comparative antibiotic eradication of mycoplasma infections from continuous cell lines," In Vitro Cellular and Developmental Biology-Animal, vol. 38, no. 2, pp. 86-89, 2002.

[16] E. Mariotti, F. D’Alessio, P. Mirabelli, N. R. Di, G. Fortunato, and V. L. Del, "Mollicutes contamination: a new strategy for an effective rescue of cancer cell lines," Biologicals, vol. 40, no. 1, pp. 88-91, 2012.

[17] R. Nir-Paz, M. C. Prévost, P. Nicolas, A. Blanchard, and H. Wróblewski, "Susceptibilities of Mycoplasma fermentans and Mycoplasma hyorhinis to membrane-active peptides and enrofloxacin in human tissue cell cultures," Antimicrobial Agents and Chemotherapy, vol. 46, no. 5, pp. 1218-1225, 2002. 

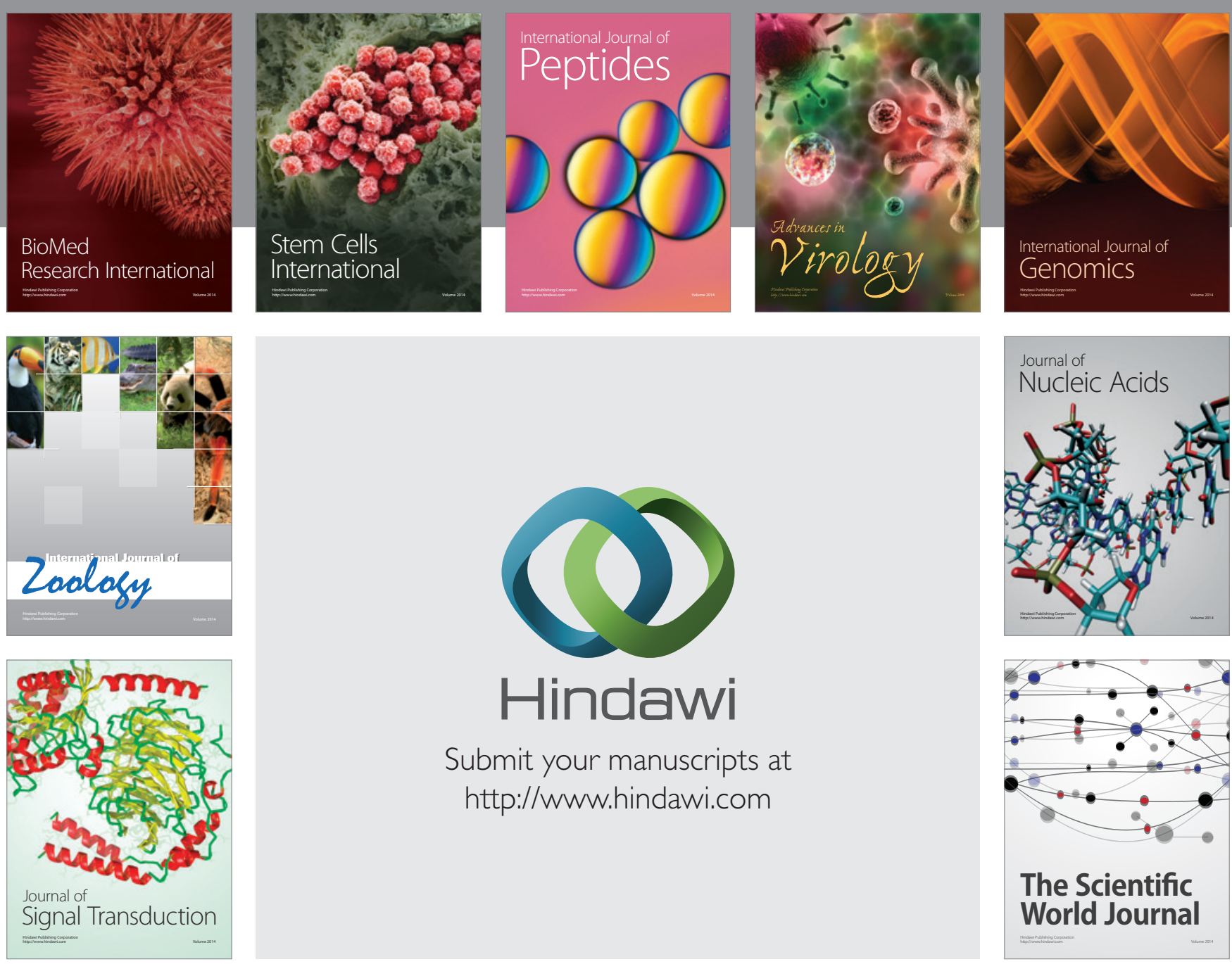

Submit your manuscripts at

http://www.hindawi.com
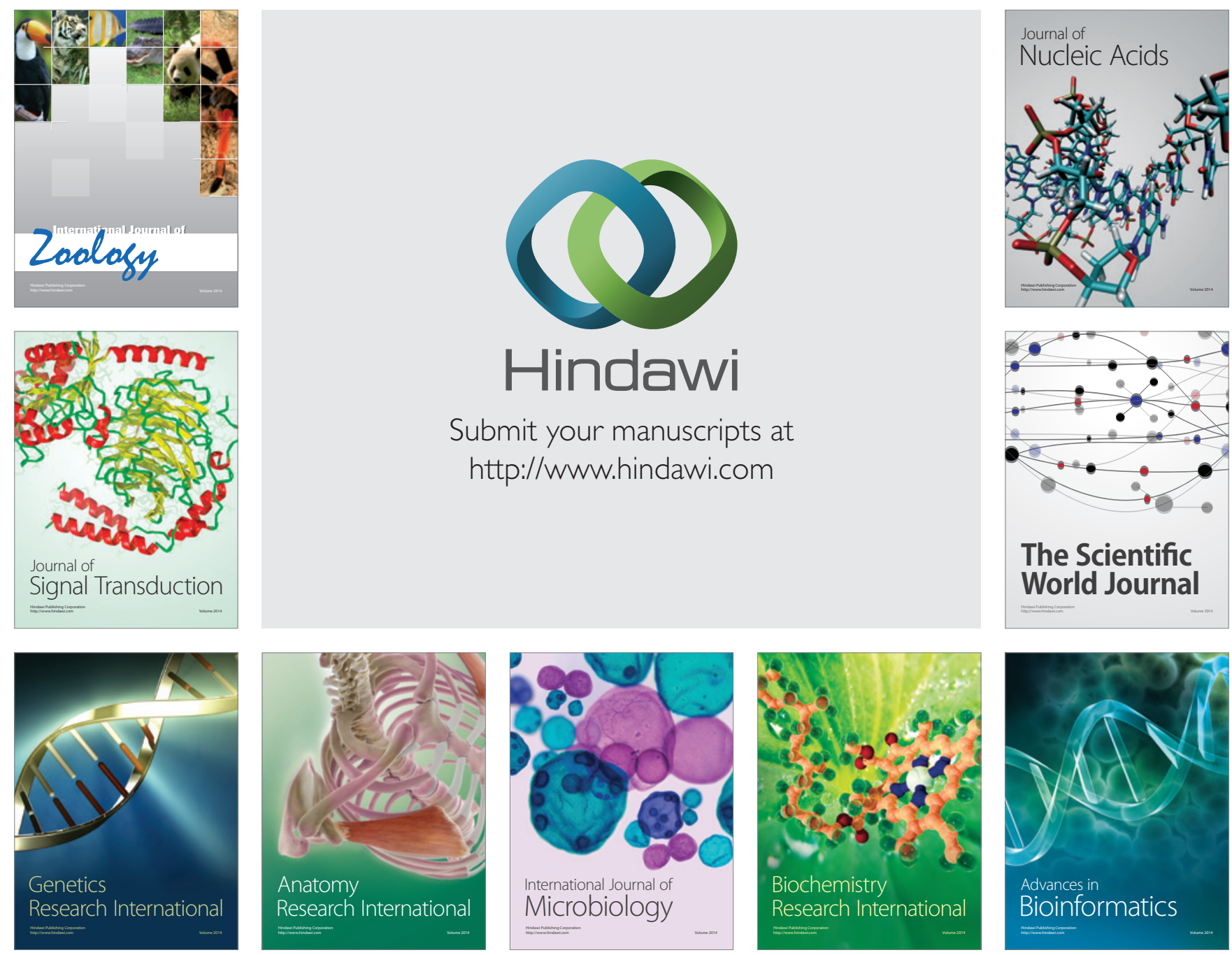

The Scientific World Journal
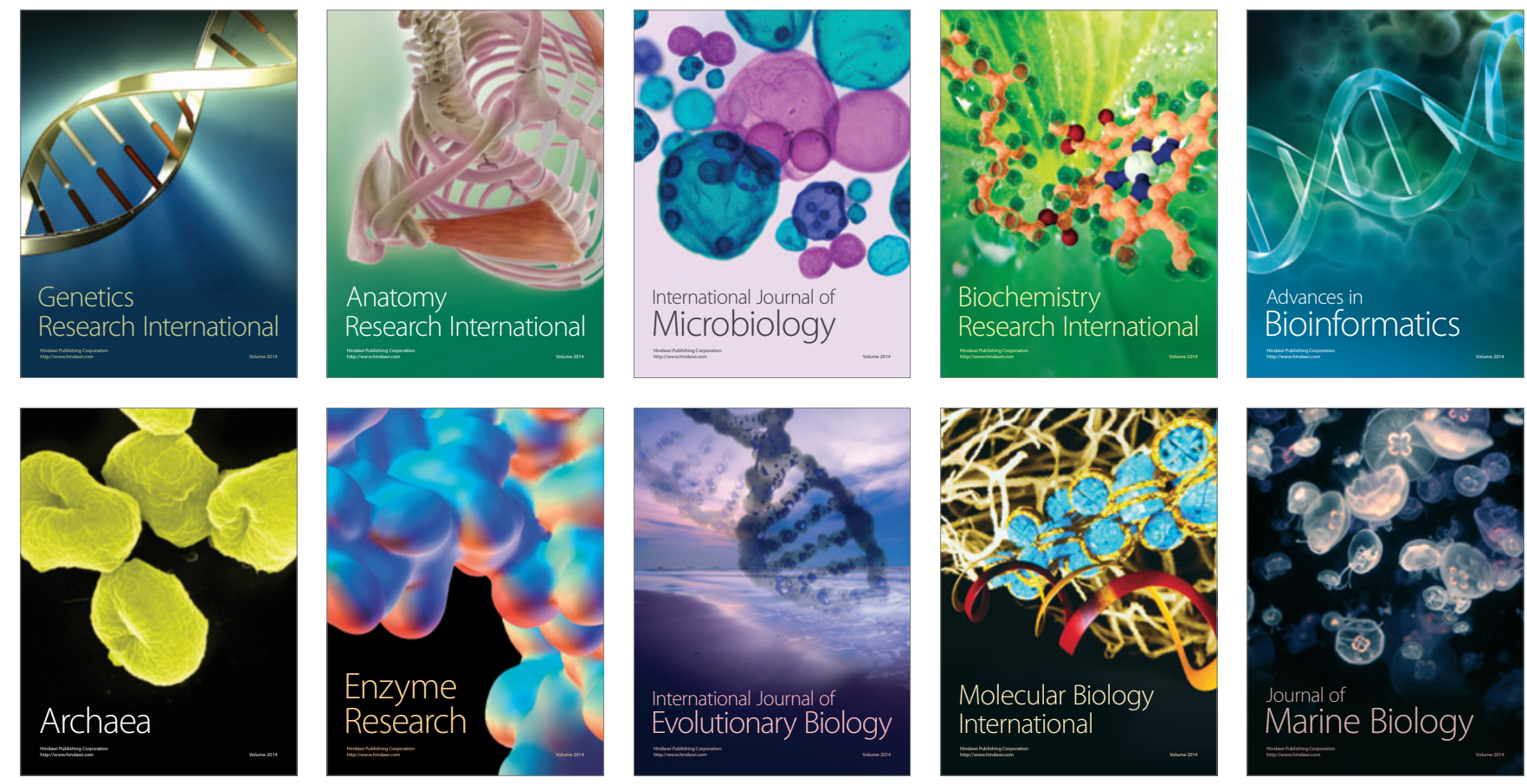